\title{
Wear Behavior of DIN 1.2210 Steel Modified by a Pulse Plasma Technique
}

\author{
Y.Y. ÖZBEK*, T. GÖKKAYA AND C.V. YAVAŞCAN \\ Sakarya University, Metallurgical and Materials Engineering Department, Esentepe Campus, 54187, Turkey
}

\begin{abstract}
The microstructure and wear properties of pulse plasma treated AISI 4140 steel was investigated. The surface properties of the materials have been improved by modifying the surfaces of the DIN 1.2210 steel with pulse plasma technique. The sample surfaces have been modified by pulse plasma with $\mathrm{C}_{3} \mathrm{H}_{8}$, nitrogen and $\mathrm{O}_{2}$ gases. Two different distances between the sample and nozzle and three different numbers of pulse were determined for modification process and the surface process was implemented by using tungsten electrode with $800 \mu \mathrm{F}$ battery capacity. The optical images were taken of the materials which the surfaces were improved by using pulse plasma technique. The surface modified samples were subjected to X-ray diffraction analysis. Wear tests were performed in a linear wear test machine with $0.15 \mathrm{~m} / \mathrm{s}$ constant sliding speed under $5 \mathrm{~N}$ loads for $200 \mathrm{~m}$ sliding distance. The wear rate was changed in accordance with process parameters. The wear resistance increased in the surface modified specimens was compared to that of non-modified ones. Worn surfaces of specimens were studied by scanning electron microscope and energy dispersive spectroscopy analyses techniques. It is determined that the thickness of modification layer changes regarding to the amount of new phases and sample-nozzle distance. It is approved the increase on wear resistance related to wolfram diffusion.
\end{abstract}

DOI: 10.12693/APhysPolA.129.588

PACS/topics: 81.15.Fg

\section{Introduction}

The huge loss occurs due to the corrosion and wear on the mechanical tools of machine and equipment. The surface properties must be improved in order to prevent this loss and to be preserved decreasing raw material stock and increasing cost [1,2]. All treatments in order to form in the surface of the workpiece that are not collectively in the workpiece are called surface treatments. As one of the new surface modification technique, the pulse plasma process is used to improve the surface properties of workpieces of tool steels [3-5]. Pulse plasma technique induces modification by causing the change of morphology on treated surface of the material. When irradiated by pulse treatment, the near surface layer of targets undergoes a rapid melt and solidification with heating and cooling rates typically in the rank of $10^{7}$ $10^{10} \mathrm{~K} / \mathrm{s}$. These rates can promote mixing, rapid diffusion, formation of amorphous or microcrystalline surface layers. Hence, the mechanical properties of material surfaces can be improved $[2-5]$. The combustion products which are sent to the system move towards to the inter electrode gap from gas chamber and the arc occurs in inner electrode. The current between anode electrode and cathode samples is required in order to implement the process. When the circuit was completed, the anode electrode vaporizes immediately and that provides the modification on sample surface. This method is highly economic, it is considered that the modification of surfaces contributes for economical in a fast period of one

\footnotetext{
*corresponding author; e-mail: yyarali@sakarya.edu.tr
}

or two minutes with pulse plasma technology.

In this work, DIN 1.2210 steel that is modified by pulse plasma is characterized with wear resistance and improved surface hardness. DIN 1.2210 steel is known as a chrome and vanadium alloyed, free machined and heat treatable cold work tool steel. It is used in the production of spiral and tap drills, broaching tools, engraving tools, ejectors, metal saws etc. [4].

In the previous studies, it is detected that the changing parameters have important effect on the grade and wear surfaces of the materials. After the optimum parameters are defined in this study, the impact of these parameters to microstructure, phase layers and wear resistance is examined.

\section{Experimental procedure}

DIN 1.2210 steel is used whose composition is given in Table I. The steel that is used in the form of rod is treated by metallographic preparation and cylindrically with $19 \mathrm{~mm}$ diameter and $5 \mathrm{~mm}$ height on CNC machine and all the samples have the same sizes. Pretreatment was not applied to the samples. The surfaces of samples were modified by using pulse plasma technology with $\mathrm{C}_{3} \mathrm{H}_{8}, \mathrm{~N}_{2}$ and $\mathrm{O}_{2}$ gases. Distance between the sample and nozzle is used as $40 \mathrm{~mm}$ and $50 \mathrm{~mm}$ and 3 different numbers of pulse $(4,8,12$ pulses) are selected for modification process. The process parameters are shown in Table II.

The workpiece surfaces of the samples were subjected to detonation process accompanied under a plasma atmosphere containing alloying elements dissolved from the metal electrode rod in interaction with the constituents of propane and nitrogen gases used for the process. The consumable electrode is tungsten and $800 \mu \mathrm{F}$ battery 
capacity is used for surface treatment. The consumable electrode was tungsten in this work. This process provided the workpiece surfaces with alloying of components of plasma and hardening of the surfaces.

TABLE I

The chemical composition of DIN 1.2210 steel.

\begin{tabular}{c|c|c|c|c}
\hline \hline wt\% C & wt\% Si & wt\% Mn & wt\% Cr & wt\% V \\
\hline 1.18 & 0.25 & 0.30 & 0.70 & 0.10
\end{tabular}

TABLE II

The Pulse Plasma Process parameters. Electrode - W, batery capacity $-800 \mu \mathrm{F}$.

\begin{tabular}{c|c|c}
\hline \hline $\begin{array}{c}\text { Sample } \\
\text { No. }\end{array}$ & $\begin{array}{c}\text { Distance between the } \\
\text { sample and nozzle }[\mathrm{mm}]\end{array}$ & $\begin{array}{c}\text { Number } \\
\text { of pulses }\end{array}$ \\
\hline 1 & 40 & 4 \\
2 & 40 & 8 \\
3 & 40 & 12 \\
4 & 50 & 4 \\
5 & 50 & 8 \\
6 & 50 & 12
\end{tabular}

The samples were etched by using $2 \%$ nital after standard metallographic process. The optic images of modified structure of sealed samples were taken with the aid of Zeiss AX10 optic microscope. The X-ray diffraction (XRD) tests of DIN 1.2210 steel that were applied to pulse plasma were done by using Rigaku X-Ray D/MAX/2200 device. The scanning electron microscopy (SEM) images from modified surfaces is taken by using JEOL, JSM 6060-LV device. Wear tests were done by using CSM-tribometer wear device. The samples and balls were cleaned with alcohol before wear test. Wear test was implemented with $6 \mathrm{~mm}$ diameter alumina ball. The applied speed was $0.10 \mathrm{~m} / \mathrm{s}$ and applied load was $5 \mathrm{~N}$ during the test. Test distance was $200 \mathrm{~m}$. Test was done in $25^{\circ} \mathrm{C}$ temperature and $30 \%$ humidity. The SEM and energy dispersive spectroscopy (EDS) analysis were applied after wear test.

\section{Results and discussions}

After pulse plasma treatment, the treated samples' cross-sections were examined by an optical microscope. The micrograph obtained from the modified surface was shown in Fig. 1. The modified layer can be easily seen by contrast of different layers. The microstructural morphology in modified layer differs from surface to center. These treatments induce very fast heating, melting and cooling in the surface layer of the DIN 1.2210 steel. The grain size was changed after pulse plasma treatment by fast cooling $[3,4]$.

Figure $1 \mathrm{a}-\mathrm{c}$ shows that the measured modified layer thickness varies. The thickness of the modified layer is increased with increasing number of pulse plasma due to the greater diffusion of atoms into the surface at higher temperatures as well as longer times [2].
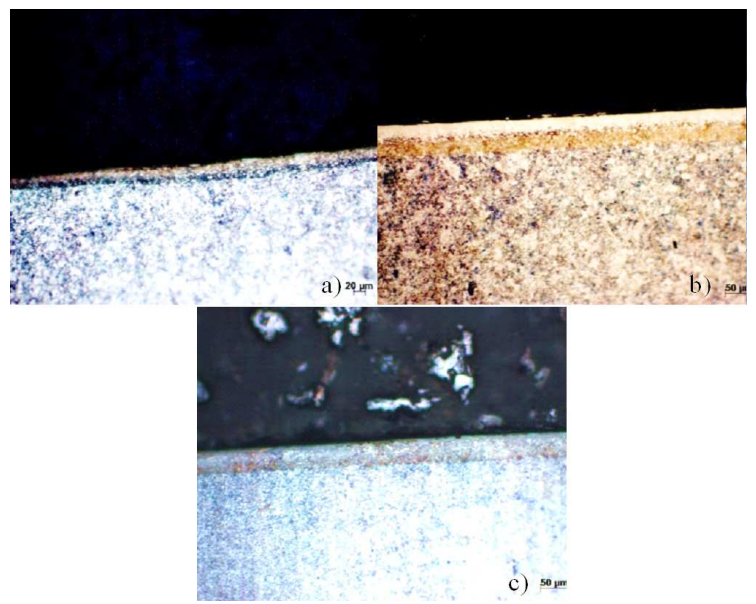

Fig. 1. The optical micrograph of (a) samples 1, (b) sample 2, (c) sample 3.

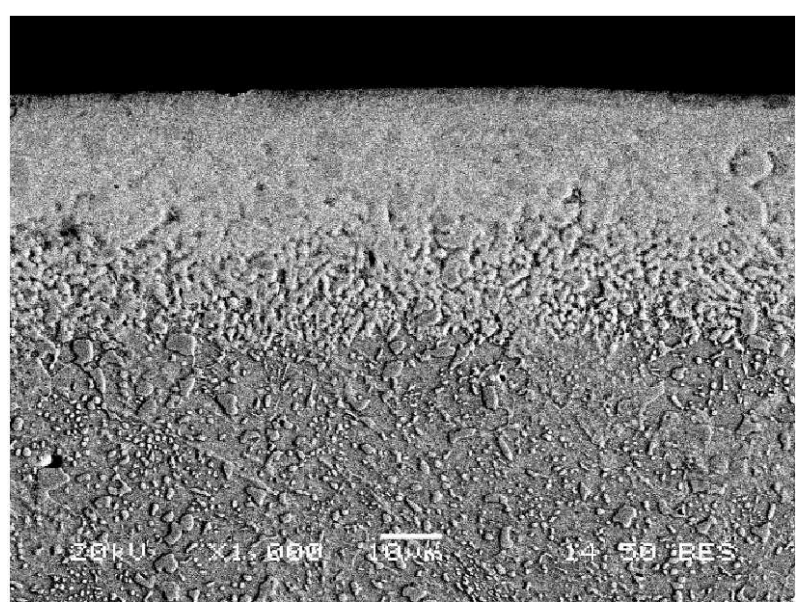

Fig. 2. The SEM micrograph of sample 4.

For the 4 pulsed samples, a solid state transformation occurred during cooling in the top surface melted layer due to the short melt duration [5-7]. In contrast, the top surface chemistry is homogenized after 12 pulses. Consequently, the austenite at top surface layer is stabilized by its high $\mathrm{C}$ concentration and its ultrafine grain size. However, the ionized gas amount increases with an increase in pulse number. As a result of this increment, the elements (W and $\mathrm{N}$ ) are distributed homogeneously through modified layer. Figure 2 shows the SEM analyses of sample 4 and the modified layer can be seen easily. The dendrite structures were seen as a result of fast heating-cooling.

Figure 3 shows the XRD traces of untreated sample and samples 1,2 , and 3 . The XRD patterns were obtained after pulse plasma treatment from the surface layer of the modified specimens at different parameters. Only one phase was detected in untreated sample, but after pulse plasma treatment new phases such as $\mathrm{Fe}_{3} \mathrm{~N}$, FeN, and tungsten phases were formed on surface [3-5]. These phases were important for surface properties.

The results of wear test with respect to different pulse numbers are shown in Fig. 4. The different pulse numbers 


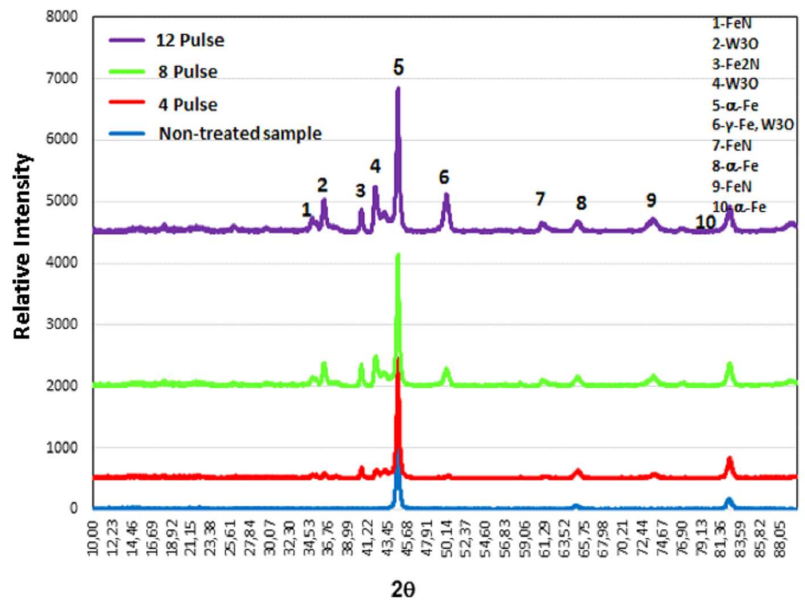

Fig. 3. X-ray analysis results of untreated sample and sample 1 (40 mm, 4 pulse), sample 2 ( $40 \mathrm{~mm}, 8$ pulse), sample 3 (40 $\mathrm{mm}, 12$ pulse).

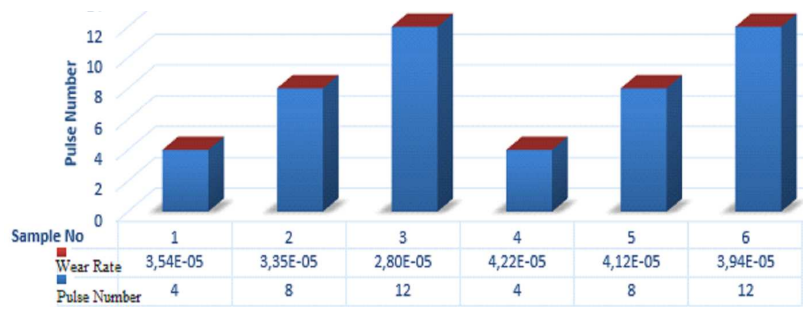

Fig. 4. The relationship between the wear rate and pulse number and distance for $5 \mathrm{~N}$ load.

as 4,8 , and 12 were used and different distances were selected such as $30 \mathrm{~mm}$ and $40 \mathrm{~mm}$. The wear resistance of the modified surface increases with increasing number of pulses. The wear rate decreases with increasing number of pulses. During the process some chemical changes occur in the surface layer, for example, ionized nitrogen causes the occurrence of nitride phases and tungsten-rich phases were detected. These improve the

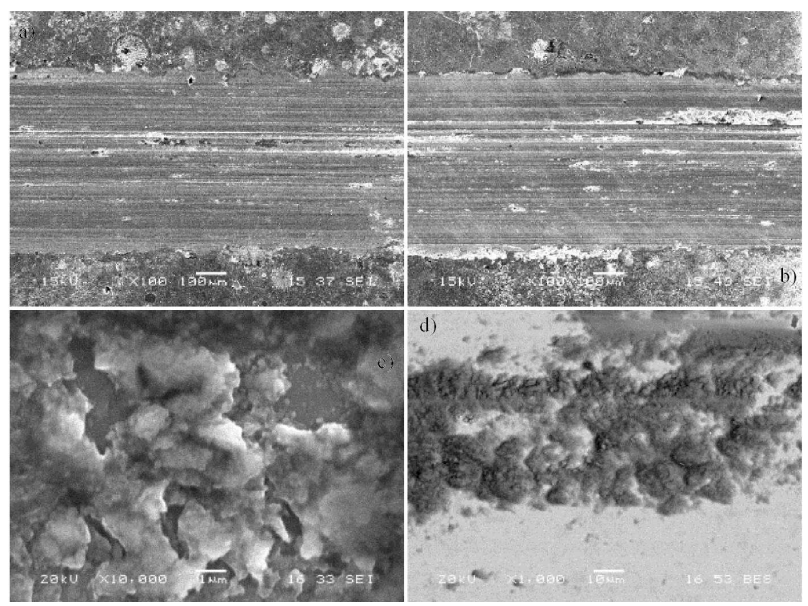

Fig. 5. SEM images for (a) the wear track of sample 1, (b) the wear track of sample 2, (c) the worn surface of the sample 3 , (d) the worn surface of sample 5. tribological properties of steel. However, the presence of nitrogen and tungsten phases can be explained by the greater improvement of tribological properties occurring for nitrogen than for pulse plasma treatment [6-8]. Figure $5 \mathrm{a}$ and $\mathrm{b}$ shows the wear tracks of the sample 1 and sample 2. Figure 5c and d shows worn surface for samples 3 and 5 . The worn surfaces showed seizure of the wear debris on the sliding surface and subsequent plastic deformation hardening evidenced by microcracks on the surface [9]. The wear debris and surface layer delaminating were observed at the modified surface. The EDS analyses results of sample 4 can be seen in Fig. 6 and Table III. The wear debris was on surface and it comes from alumina ball.

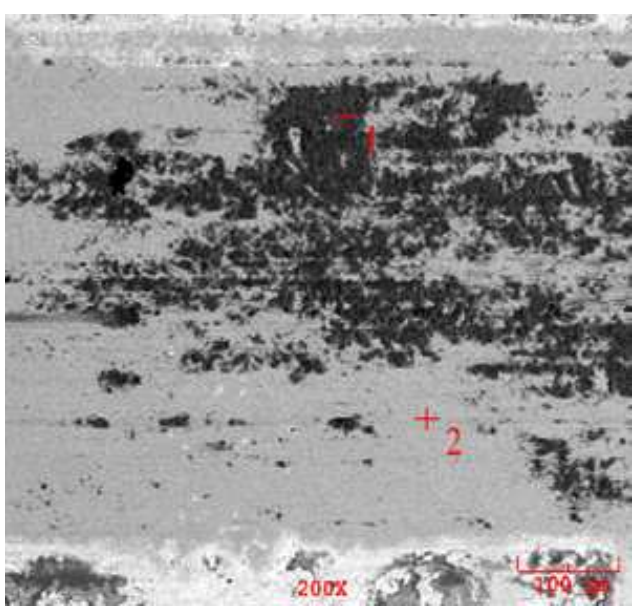

Fig. 6. EDS analyses results of points on sample 4.

TABLE III

EDS analyses of sample 4.

\begin{tabular}{c|c|c}
\hline \hline Elt. & $1 .[\mathrm{wt} \%]$ & $2 .[\mathrm{wt} \%]$ \\
\hline $\mathrm{C}$ & 0.561 & 0.000 \\
$\mathrm{O}$ & 27.053 & 7.729 \\
$\mathrm{Al}$ & 0.012 & 0.293 \\
$\mathrm{Si}$ & 0.222 & 1.149 \\
$\mathrm{~S}$ & 0.831 & 0.309 \\
$\mathrm{Fe}$ & 68.968 & 87.994 \\
$\mathrm{~W}$ & 2.352 & 2.526
\end{tabular}

\section{Conclusion}

It can be seen that, in this work, the pulse plasma system improved some surface properties. The process parameters namely nozzle distance and number of pulses played an important role in changing the surface properties. The microstructure of the surface layer in all of the plasma-modified specimens consisted of a compound layer and a diffusion zone from the surface inward. The new phases such as $\mathrm{Fe}_{3} \mathrm{~N}, \mathrm{~W}_{3} \mathrm{O}, \mathrm{W}, \gamma-\mathrm{Fe}$ occurred in the surface modified by pulse plasma treatment. The wear resistance of surface was approximately 2 or 3 times greater due to the change in modified surface. 


\section{References}

[1] Y. Sahin, M. Erdogan, V. Kilicli, Mater. Sci. Eng. A 444, 31 (2007).

[2] Yu. Chivel, O. Kuznechik, Surf. Coat. Technol. 205, S347 (2011).

[3] Y.Y. Özbek, M. Durman, H. Akbulut, Tribol. Trans. 52, 213 (2009).

[4] www.osmanli-bohler.com/upload/pdf/soguk/K510.pdf, Şubat-2015.

[5] C.X. Li, Y. Sun, T. Bell, Mater. Sci. Eng. A 292, $18(2000)$.
[6] S.Y. Sirin, K. Sirin, E. Kaluc, Mater. Character. 59, 351 (2008).

[7] Y.Y. Ozbek, C. Sarioglu, M. Durman, Vacuum 106, 11 (2014).

[8] V.V. Uglov, V.M. Anishchik, N.N. Cherenda, Yu.V. Sveshnikov, V.M. Astashynski, E.A. Kostyukevich, A.M. Kuzmitski, V.V. Askerko, Surf. Coat. Technol. 202, 2439 (2008).

[9] E. Gualtieri, A. Borghi, L. Calabri, N. Pugno, S. Valeri, Tribol. Int. 42, 699 (2009). 